\title{
Assessment of the Structural Integrity of Timber Utility Poles Using Ultrasonic Waves
}

\author{
Jad EI Najjar ${ }^{1, a}$ and Samir Mustapha ${ }^{2, b,{ }^{*}}$ \\ ${ }^{1}$ American University of Beirut, Ashrafieh Beirut, Lebanon \\ ${ }^{2}$ American University of Beirut, Ain El-Mraisse Beirut, Lebanon \\ ajje11@mail.aub.edu, bsm154@aub.edu.lb
}

Keywords: Structural Health Monitoring, Timber Utility Poles, Guided Waves, Macro Fiber Composites, Damage Detection, Embedded Length Assessment

\begin{abstract}
In this study, guided stress waves were used to evaluate the conditions of a timber utility pole experimentally and numerically using COMSOL Multiphysics. Macro Fiber Composites (MFCs), due to their flexibility and convenience to install on curved surfaces, were used to actuate and sense guided waves along the tested specimens. Based on the wave propagation characteristics in these types of structures, an MFC actuator ring, which was developed in the previous work, was applied to tune and enhance the propagating wave modes of interest. The designed ring was used to excite longitudinal ultrasonic wave modes, mainly $\mathrm{L}(0,1)$, for the purpose of determining the embedded length of the pole. For the damage localization a single MFC excitation was used which proved to be more efficient than the actuator ring. Embedding the timber in soil had minimum impact on the wave propagation characteristics, given that the waves were confined in the timber pole with minimal leakage to the surrounding. The embedded length was determined accurately for sound and damage timber, using both experimental and numerical data with an error of less than $3 \%$. The deterioration in the timber structure, within the embedded region, was also evaluated with high accuracy of 93 $\%$. Based on the obtained results, guided waves have high potential to be used as a nondestructive tool for the assessment and evaluation of timber utility poles.
\end{abstract}

\section{Introduction}

The use of timber has commenced thousands of years ago and is still being used today in numerous applications. Being easy to manufacture and customize, practices vary from construction work, transportation applications, equipment, and infrastructure. When treated properly, timber can act as a substitute for many renowned materials such as steel and concrete. The cost of transportation and storage is low compared to other materials, in addition to the ability to withstand handling and surface damage due to the lightweight and tough properties ${ }^{[1]}$. When evaluating the integrity of timber utility poles, two parameters are mainly examined and correspond of the embedded length of the pole and the presence (position) of damage or decay in the embedded section ${ }^{[2]}$. Currently, surface non-destructive techniques are the most common in timber structures where longitudinal (compressional) and flexural (bending) stress waves are used for the evaluation process. These techniques include sonic echo (SE) and impulse response (IR) tests, where the embedded length and health state of the timber can be evaluated. Condition assessment of timber poles can be performed using guided waves where the presence of decay or damage can be detected. Various studies on this matter have been conducted with the use of machine learning techniques. Dackermann et al. ${ }^{[3]}$ used support vector machines (SVM) on a network of tactile transducers that generate guided waves in timber poles. Different damage 
cases were conducted on several timber and concrete pole specimens where the SVM was used to generate classification results for predicting damage conditions. Other signal processing techniques such as fast Fourier transform (FFT) and principal component analysis (PCA) were also used to process data from damaged specimens. In another study, Dackermann et al. [4] presented machine learning methods for pattern recognition to assess the health condition of timber poles. Guided waves were actuated and captured using a multi-sensor array mounted on the pole. Damage detection using a hierarchical data fusion algorithm was applied on timber poles in ${ }^{[5]}$ with the use of guided waves. Multi-sensor arrays were also used in the model where the hierarchical approach lead to an enhanced accuracy when detecting damage in the timber pole.

In this study, guided waves have been used for the assessment of timber poles numerically using COMSOL Multiphysics and experimentally. Important features such as the embedded length and the health state of the timber pole has been evaluated by the means of Macro Fiber Composites (MFCs) (Smart Material corp., 2017). The application of an MFC-ring assisted in the generation of purely longitudinal wave modes, such as mode $\mathrm{L}(0,1)$, which were used in the evaluation process. The excitation frequency was selected according to a set of factors such as the number of propagating wave modes, dispersion and the number of MFCs required in the actuator ring. The effect of change in boundary conditions (traction free and soil embedment) on the length estimation and damage assessment was also investigated.

\section{Numerical FEA Model}

Dispersion curves were generated using DISPERSE software ${ }^{[6]}$ for a transversely isotropic timber pole, for the specimen under-study, with properties shown in Table 1. The group velocity can be directly used to characterize the propagating wave modes and can be calculated using the central transit time of each propagating packet. Propagating wave modes in circular structures are dependent on the circumferential order $n^{[7]}$. Torsional modes $T(n, m)$ involve the azimuthal component of the displacement vector, and longitudinal modes $\mathrm{L}(\mathrm{n}, \mathrm{m})$ involve both radial and axial components of the displacement vector with $n=0$ where they propagate with axial symmetry along the cylinder ${ }^{[7]}$. Flexural wave modes are much more complicated and are nonaxisymmetric with all three components of the displacement vector. For every circumferential order $\mathrm{n} \geq 1$, there exists a flexural wave mode of a given family ${ }^{[7]}$. Group velocity plots for longitudinal and flexural waves of first order are displayed in Fig. 1.

Table 1 Material properties of transversely isotropic white pine timber ${ }^{[8]}$.

\begin{tabular}{|c|c|c|c|c|c|c|c|}
\hline Property & $\mathrm{E}_{\mathrm{L}}(\mathrm{GPa})$ & $\mathrm{E}_{\mathrm{R}}(\mathrm{GPa})$ & $\mathrm{E}_{\mathrm{T}}(\mathrm{GPa})$ & $\mathrm{G}_{\mathrm{LR}}(\mathrm{GPa})$ & $\mathrm{G}_{\mathrm{LT}}(\mathrm{GPa})$ & $\mathrm{G}_{\mathrm{RT}}(\mathrm{GPa})$ & $\rho\left(\mathrm{kg} / \mathrm{m}^{3}\right)$ \\
\hline Value & 11.11 & 0.866 & 0.866 & 0.577 & 0.577 & 0.533 & 380 \\
\hline
\end{tabular}




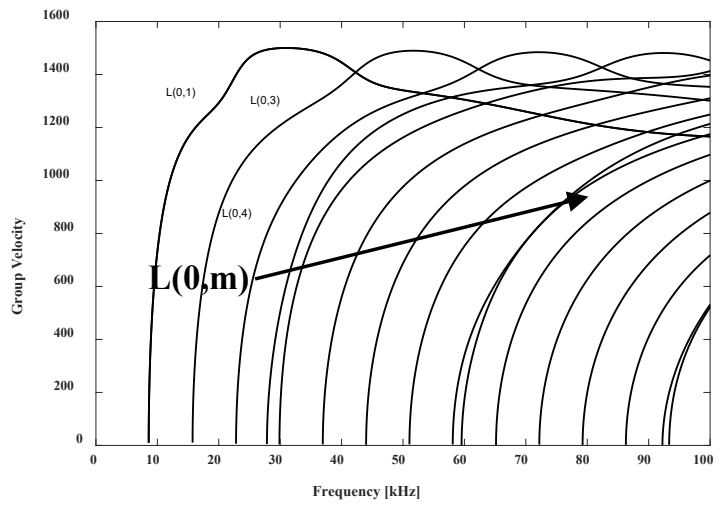

(a)

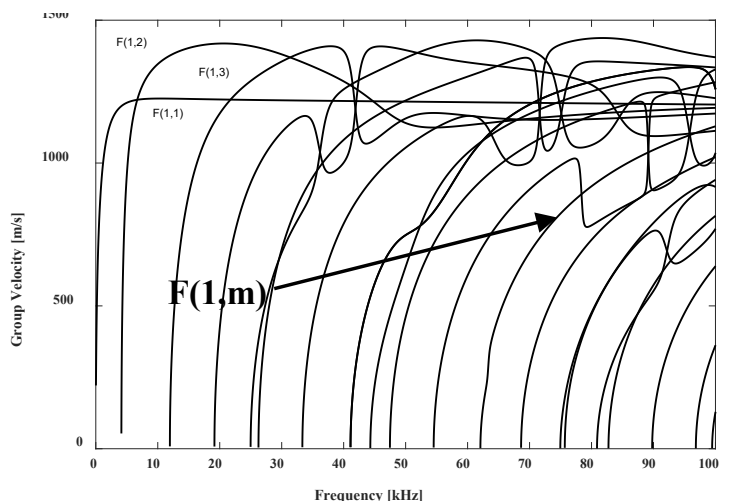

(b)

Fig. 1 Dispersion curves: Group velocity versus frequency for (a) longitudinal and (b) flexural wave modes.

Ring Design and Wave Mode Tuning. For the assessment of timber poles, it is important to tune the propagating modes based on the dispersion curves. The high number of waves, from the dispersion curves, was shown to be present even at low frequencies with a significant effect of dispersion. In particular, flexural modes are more complicated than longitudinal ones and are present in high orders (for $n \geq 1$ ). The generation of non-axisymmetric wave modes (flexural modes) can be restricted by the excitation of a transducer ring of piezoelectric elements, equally spaced around the circumference of the pole ${ }^{[9]}$. This configuration suppresses flexural modes and enhances the propagation and reflections of longitudinal waves present at the frequency of excitation. In order to suppress flexural modes, the total number of transducers placed around the circumference must be greater than or equal to the highest circumferential order (m) of flexural modes propagating at the excitation frequency ${ }^{[9]}$. From the dispersion curves shown in Fig. 1 (b), there exist $F(4, \mathrm{~m})$ with the highest circumferential order of 4 at $12.5 \mathrm{kHz}$. This means that a minimum of 4 MFCs must be mounted, equally spaced around the circumference, to suppress the propagating flexural modes at this excitation frequency. At higher frequencies, the maximum circumferential order is $>7$ which requires the actuation of $>8$ MFCs around the circumference. In our design, the excitation frequency was selected at $12.5 \mathrm{kHz}$ and the MFC ring consisted of 8 elements. This will allow us to experiment three different actuation configurations corresponding of single, four and eight-MFCs. The verification of exciting an MFC ring around the pole's circumference was depicted in our previous study ${ }^{[10]}$. By actuating multiple MFCs in the ring, unwanted flexural modes were suppressed, and the longitudinal modes propagated with an enhanced amplitude.

Effect of Boundary Conditions and Damage Induction. The evaluation of embedded length and health state of a timber pole was scrutinized numerically using COMSOL Multiphysics ${ }^{\text {[1] }}$ by examining the propagation of guided waves in traction free and embedded boundary conditions. For utility poles in specific, the recommended embedment depth is $10 \%$ of the total pole's length plus $2 \mathrm{ft}(61 \mathrm{~cm})$. The total length of the pole modeled in COMSOL was 5.5 meters, in order to account for a suitable embedment length of 1.45 meters. This selected length was the expected value of an in-service embedded utility pole with an 8-meter length For the soil - timber interface, a contact node was added to the common surface between both timber and soil where the contact pressure method used was Penalty. Damage was introduced to the timber structure in the embedded section by removing a small section of the timber. The numerical 
model for damaged timber was simulated for traction free and embedded models with the application of the MFC ring. Fig. 2 (a) and (b) shows the MFC actuator and sensors placement along with the embedded boundary condition for the damaged model. As for applying mesh to the model, the wavelength found from the dispersion curves were used to calculate the mesh size, where an average of 6-10 elements per wavelength is required [12, 13]. Additional convergence tests were performed on the calculated mesh size and yielded $5.5 \mathrm{~mm}$, with around 16 elements per wavelength.

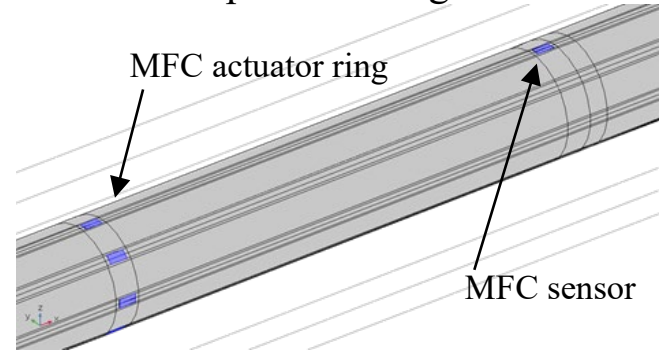

(a)

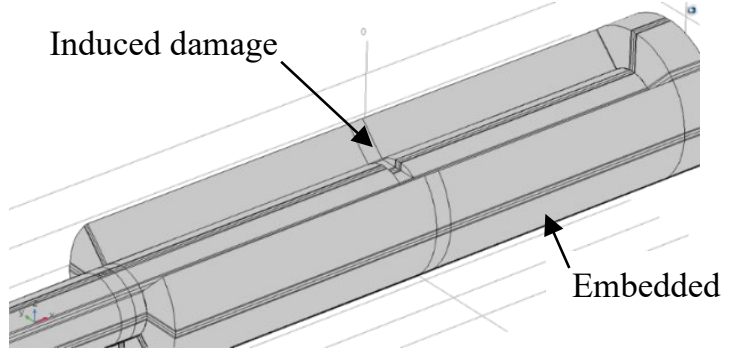

(b)

Fig. 2 5.5-meter timber pole in COMSOL: (a) actuator ring and sensor placement and (b) embedded boundary condition for the damaged structure.

\section{Experimental Setup}

One of the most common types of timber in the electric distribution industry (utility poles) is Scots pine (also known as Pinus Sylvestris ${ }^{[14]}$ or white pine) which was used in the experimental setup. A validation process was undergone on an 8-meter timber pole where the effect of change in boundary conditions and damage induction was inspected. Multiple MFC actuation configurations (MFC ring) for tuning the propagating waves were tested to determine the embedded length and location of the damage. The embedded length corresponds to the distance between the MFC sensor and bottom edge of the pole, and the damage location corresponds of the distance between the sensor and the damage. MFCs of type M-2814 P1 were coupled to the pole's surface using Loctite's E120 HP epoxy adhesive at different locations along the specimen. In order to create an arrangement where the variable is the embedded condition, a wooden box was inserted at the back end of the pole where soil can be added and removed. Fig. 3 (a) displays the simply supported 8-meter pole where the bottom section was inserted into the box. The testing was only performed on the bottom end of the pole, which was the location of interest, to evaluate the embedded section and acquire less reflections from the top end of the pole. Last, the frequency of excitation was selected at $12.5 \mathrm{kHz}$ and the actuator ring contained $8 \mathrm{MFCs}$, similar to the numerical model. The actauator ring and sensor placement are shown in Fig. 3 (b).

A damage was induced in the structure where the timber pole was cut in the section located inside the wooden box (embedded section). The experiments were performed for traction free and embedded conditions for sound (pre-damage) and damaged timber to investigate the effect on guided waves and embedment length estimation. The location of the damage was determined from the setups for both boundary conditions. Fig. 3 (c) shows the damage created in the section of the pole, prior to soil embedment. To avoid variations during the experiment, all setups were performed simultaneously. To simulate the embedded condition, soil was added gradually to the wooden box and compressed at each layer to provide as much contact as possible with the surface of the timber pole. 


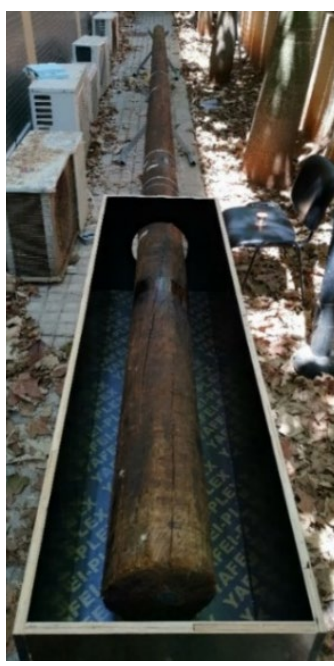

(a)

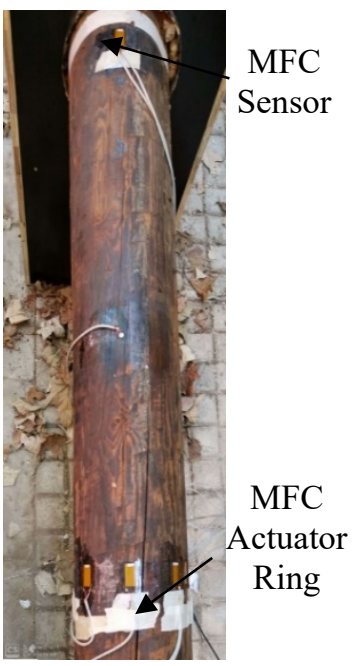

MFC

Ring

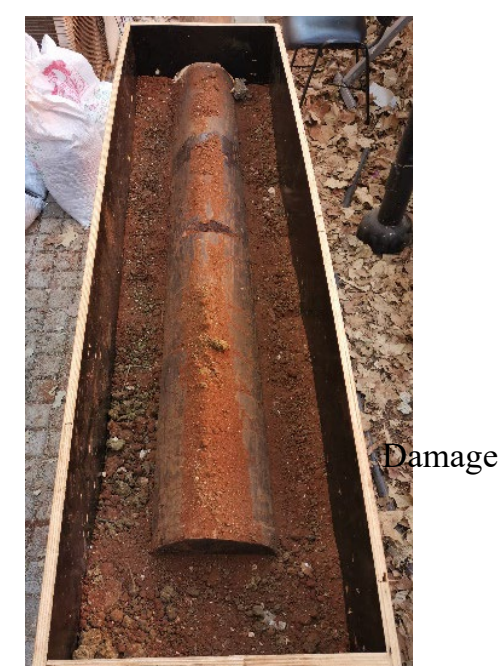

(c)

Fig. 3 (a) 8-meter timber utility pole, (b) MFC actuator ring and sensor configuration and (c) Induced damage in the embedded section of the pole.

Data Acquisition. The equipment used in the experimental setup were a Keysight 33500B signal generator, EPA-104 Piezo System Inc amplifier, and Keysight InfiniiVision DSO-X3024A oscilloscope. The generated 5-cycle Hanning window input signal to the actuator was passed through the signal amplifier which increased the gain to $300 \mathrm{~V}$ peak to peak. Signals from the sensors were then acquired using the oscilloscope at a sampling rate of $2 \mathrm{MHz}$.

\section{Results and Analysis}

Effect of Boundary Conditions. The effect of boundary conditions on determining the embedded length was scrutinized numerically and experimentally on a 5.5-meter and 8-meter timber pole respectively. Multiple MFC configurations were actuated separately which correspond to single, 4-ring and 8-ring actuation at the selected frequency of excitation. Wave mode characterization and the effect of soil are analyzed in this section, for sound timber prior to damage induction. The numerical results acquired were decomposed using the improved complete ensemble empirical mode decomposition with adaptive noise (CEEMDAN) signal processing technique, providing a better understanding of the difference between the two boundary conditions. This method decomposes the input signal into modes that are composed of multiple frequency and amplitude modulated functions. The sum of these modes, or intrinsic mode functions (IMFs), form the complete initial input signal ${ }^{[15]}$. The IMFs generated can help identify mode reflections and compare two signals more accurately.

Analyzing the acquired numerical signals for sound timber (single MFC atuation) shown in Fig. 4, the reflections from the propagating wave modes appear to have slightly higher amplitudes in the embedded boundary condition than the traction free one. This indicates that not only the wave is contained inside the pole in the embedded condition, but also there is less leakage in soil than in air. Packets arriving at times 4E-3, 4.65E-3 and 5.2E-3 seconds have a higher amplitude in the embedded condition. From Fig. 4, the bulk wave propagates at $5000 \mathrm{~m} / \mathrm{s}$ and arrives at the beginning of the signal, with its reflections from both ends of the pole present at around 1E-3 seconds and 2E-3 seconds. This bulk wave appears to be non-dispersive where the 5-peak packet maintains its shape as shown in the first and second arrival of the wave, with no change in the frequency components. Flexural modes propagate at $2540 \mathrm{~m} / \mathrm{s}$ and $1429 \mathrm{~m} / \mathrm{s}$ indicating $F(1,1)$ and $F(1,2)$. Their reflections arrive at $2 \mathrm{E}-3$ and $3 \mathrm{E}-3$ from the bottom of the 
pole. $\mathrm{F}(1,1)$ second reflection from the top end arrives right before $4 \mathrm{E}-3$ seconds. Also, flexural mode $\mathrm{F}(4,1)$ of order 4 propagates at $625 \mathrm{~m} / \mathrm{s}$. The rest of the high order flexural modes are not indicated in the figure for simplification purposes. Nevertheless, longitudinal modes $\mathrm{L}(0,1)$, $\mathrm{L}(0,2)$ and $\mathrm{L}(0,3)$ propagate at $980 \mathrm{~m} / \mathrm{s}, 780 \mathrm{~m} / \mathrm{s}$ and $508 \mathrm{~m} / \mathrm{s}$ respectively. Their reflections are also indicated in the figure, where $\mathrm{L}(0,1)$ and $\mathrm{L}(0,2)$ arrive at $4 \mathrm{E}-4$ and $4.5 \mathrm{E}-3$ seconds. The 5.5meter pole provides enough distance for the waves to converge, which results in the propagation of various modes with different orders. As for the effect of soil embedment, no significant effect on flexural mode's first reflections is shown. However, for the second reflection of $F(1,1)$ and the first reflection of $\mathrm{L}(0,1)$ and $\mathrm{L}(0.2)$. there is a notable increase in the packet's amplitude in the embedded condition.

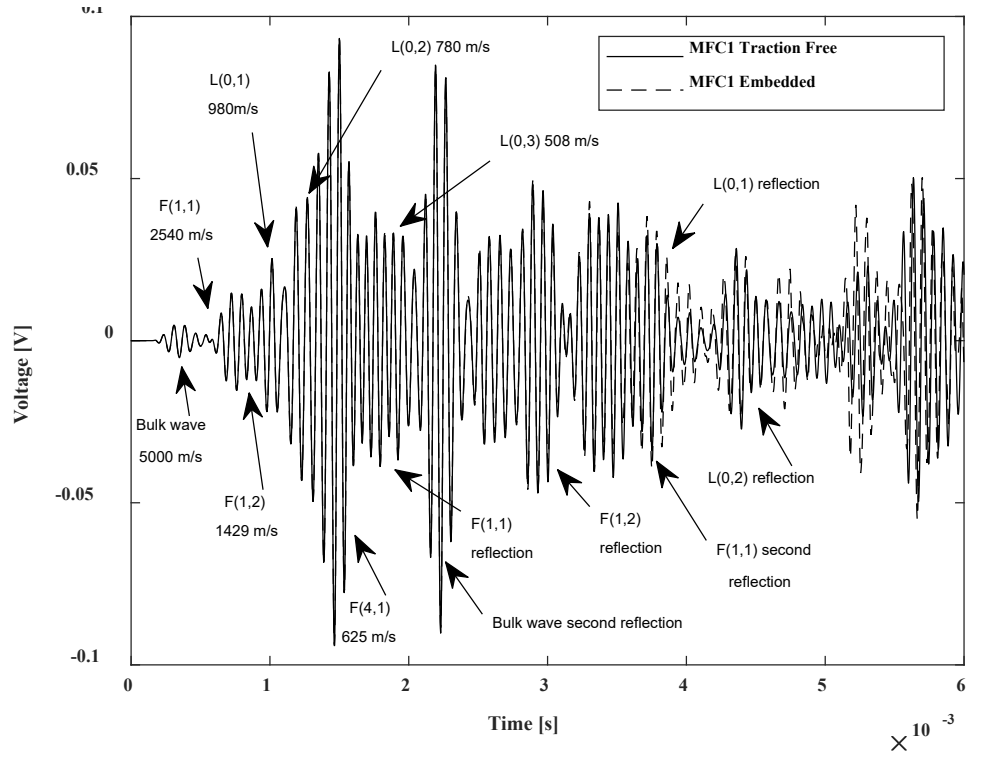

Fig. 4 Numerical results: Propagating wave modes and their reflections for traction freelembedded signals using single MFC actuation at $12.5 \mathrm{kHz}$.

Similarly, the acquired signals from the experimental single MFC actuation, traction free and embedded boundary conditions (sound wood) were placed above each other and decomposed to examine the difference. Embedding the section of the pole did not have significant effect on the reflecting packets, but rather the waves were confined within the medium with minimal leakage. It can be shown in Fig. 5 that all propagating modes are the same in traction free and embedded signals. Flexural modes $\mathrm{F}(1,1)$ and $\mathrm{F}(1,2)$ propagate at $2797 \mathrm{~m} / \mathrm{s}$ and $1768 \mathrm{~m} / \mathrm{s}$ and arrive early in the acquired signal. The longitudinal modes $\mathrm{L}(0,1)$ and $\mathrm{L}(0,2)$ arrive right after and propagate at $1140 \mathrm{~m} / \mathrm{s}$ and $845 \mathrm{~m} / \mathrm{s}$ respectively along with their reflections arriving at 4E-3 and 5.2E-3 seconds from the bottom edge. Furthermore, $\mathrm{F}(1,2)$ and $\mathrm{L}(0,2)$ reflect from a knot present at 1.2 meters to the left of the actuator, which appear in the packets at $2.6 \mathrm{E}-3$ and $3.65 \mathrm{E}-3$ seconds. The reflected packets from the knot travel a total distance of 3.2 meters. The effect of soil embedment appears only on the reflection of mode $\mathrm{F}(1,1)$ where the packet has a lower amplitude in the embedded condition. However, the rest of the modes reflected are not affected by the addition of soil, which indicates that they are confined in the timber medium with no attenuation and leakage to the outer soil medium. 


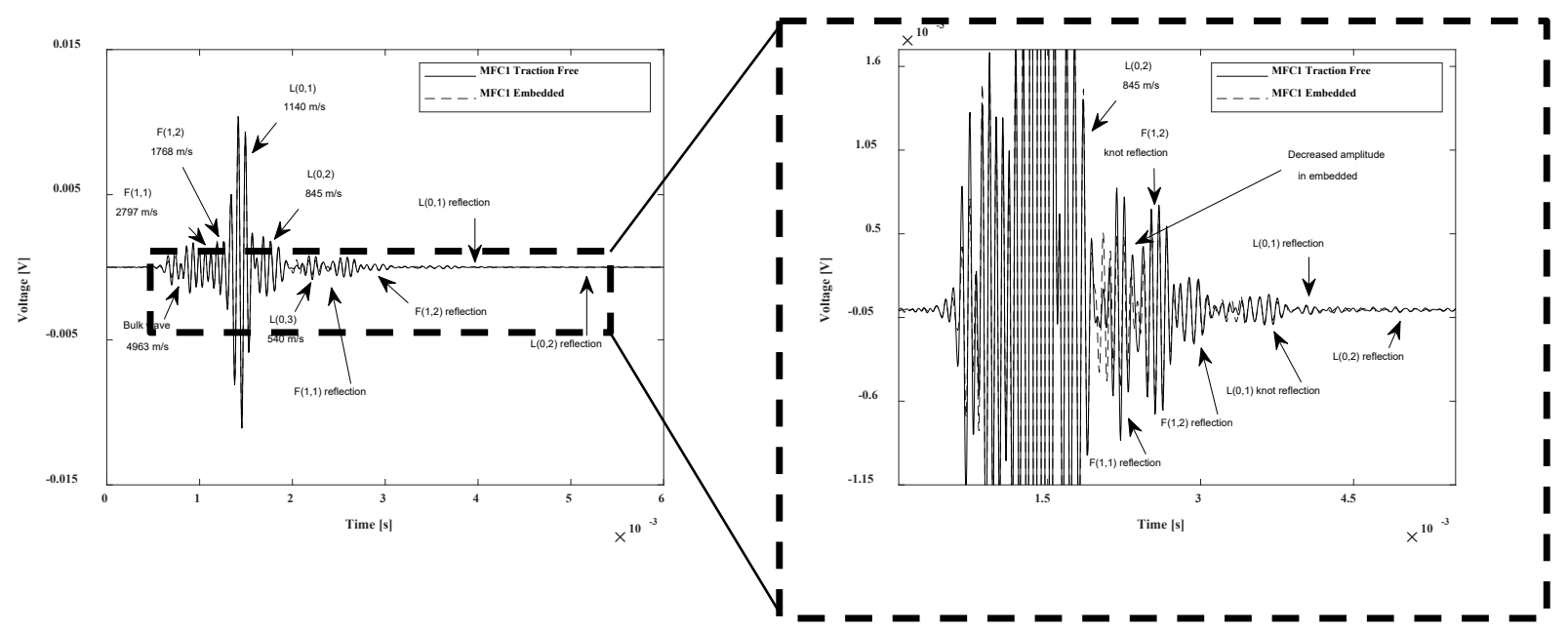

Fig. 5 Experimental results: Propagating wave modes and their reflections-traction free/embedded signals, using single MFC actuation at $12.5 \mathrm{kHz}$.

Determining the embedded length of the pole can be done by capturing the first and reflected arrival of a certain wave mode. Several modes propagate at $12.5 \mathrm{kHz}$ frequency as shown in the numerical and experimental results, where each identified reflected packet can be used for the length estimation. However, some modes are more sensitive than others with respect to the boundary conditions present, knots and cracks in the structure and the configuration of MFC actuation. Since flexural modes are unwanted due to their complexity and the presence of high order modes, the MFC ring actuation can cancel them out and simultaneously enhance the longitudinal modes and their reflections ${ }^{[16]}$, which can be used for the length estimation.

Signals acquired from actuating 4 and 8 MFCs around the pole's circumference are shown below for traction free/embedded boundary conditions. Results from the numerical model shown in Fig. 6 confirm that the actuation of multiple MFCs enhances the acquired packets in general, whether they were flexural (unsuppressed) or longitudinal wave modes. For instance, the amplitude of the direct transmission of the bulk wave, $\mathrm{L}(0,1), \mathrm{L}(0,2)$ and $\mathrm{L}(0,3)$ is higher than the ones in single MFC actuation. $\mathrm{L}(0,1)$ amplitude (direct transmission) increases by around $60 \%$ in the 4 and $8 \mathrm{MFC}$ actuation. The reflection's amplitude of mode $\mathrm{L}(0,1)$ is also enhanced in the 4 ring by $58 \%$, and $63 \%$ in the 8 ring actuation. Additionally, flexural modes $\mathrm{F}(1,1)$ and $\mathrm{F}(1,2)$ do not appear to propagate in both MFC ring actuations, meaning they were completely suppressed. However, from Fig. 6 (a) mode $F(4,1)$ still propagates at $630 \mathrm{~m} / \mathrm{s}$ in the 4 ring actuation where it was not suppressed due to its higher circumferential order. The results from actuating 8 MFCs shown in Fig. 6 (b) confirm the suppression of all flexural modes, including mode $\mathrm{F}(4,1)$. Comparing the traction free and embedded signals, no significant difference can be identified as observed in the case of the single MFC actuation. When actuating 4 and 8 MFCs around the circumference, the effect of soil/air on the longitudinal modes' reflections decreases. However, mode $\mathrm{L}(0,2)$ was the most affected by the soil embedment where it had a slightly higher amplitude than the traction free condition. Reflection of longitudinal mode $\mathrm{L}(0,1)$ had the same amplitude in the two boundary conditions. 


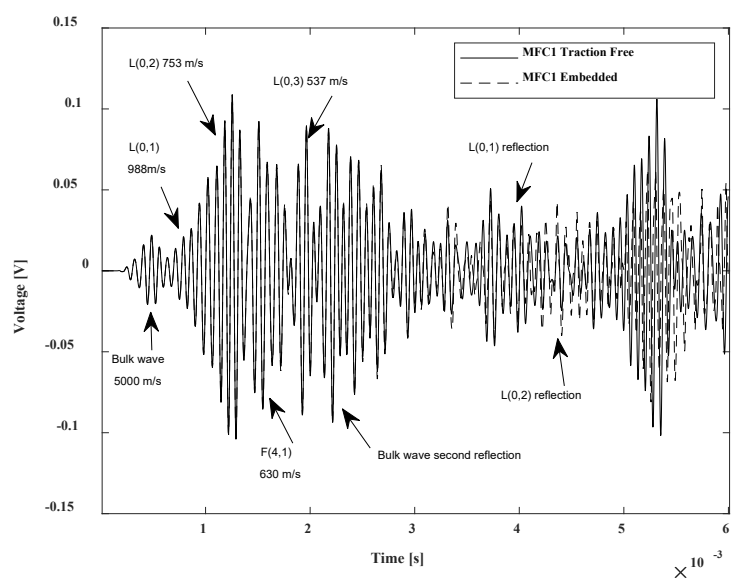

(a)

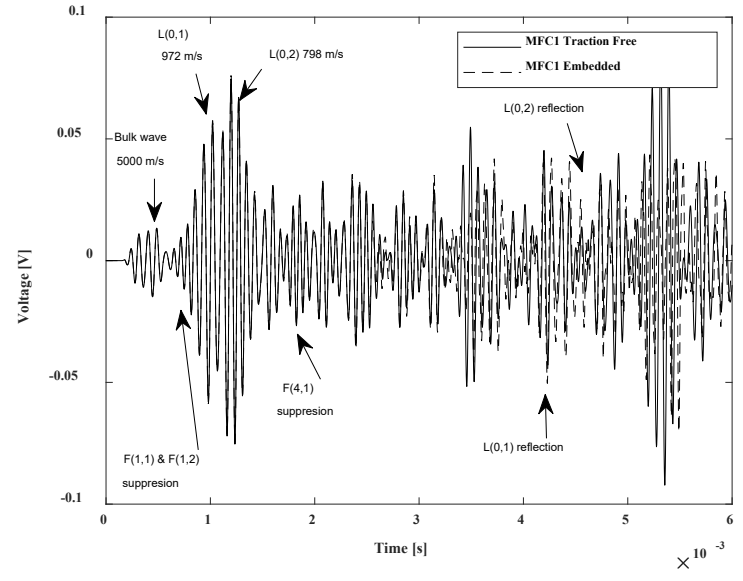

(b)

Fig. 6 Numerical results: Propagating wave modes and their reflections for traction free/embedded signals using (a) 4-Ring and (b) 8-Ring MFC actuation at $12.5 \mathrm{kHz}$.

In the experimental testing, the MFC ring actuation also yields similar results as the numerical. Fig. 7 shows the acquired signal for traction free and embedded conditions using 4 ring (a) and 8 ring (b) MFC actuation. The bulk wave, $\mathrm{L}(0,1)$, and $\mathrm{L}(0,2)$ attained higher amplitudes than the single MFC actuation. The direct transmission enhancement of the longitudinal modes is around $30 \%$ in both ring actuations, whereas the reflection enhancement is $80 \%$ and $93 \%$ in the 4 and 8 ring actuations. Regarding the suppression of flexural modes, the 4 ring actuation was not enough to suppress $F(1,1)$ which arrives at $1 \mathrm{E}-3$ seconds as shown in Fig. 7 (a). However, in the 8 ring actuation shown in Fig. 7 (b), all flexural modes including F(1,1) were suppressed. The rest of the propagating wave modes and their reflections are indicated on the figures. The acquired signals are almost entirely similar for traction free and embedded conditions in both MFC ring actuations, where the effect of soil embedment seems negligible.

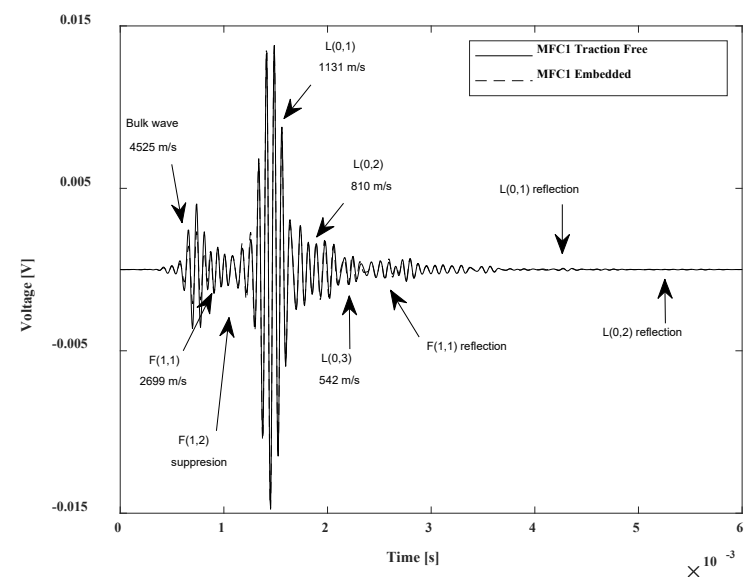

(a)

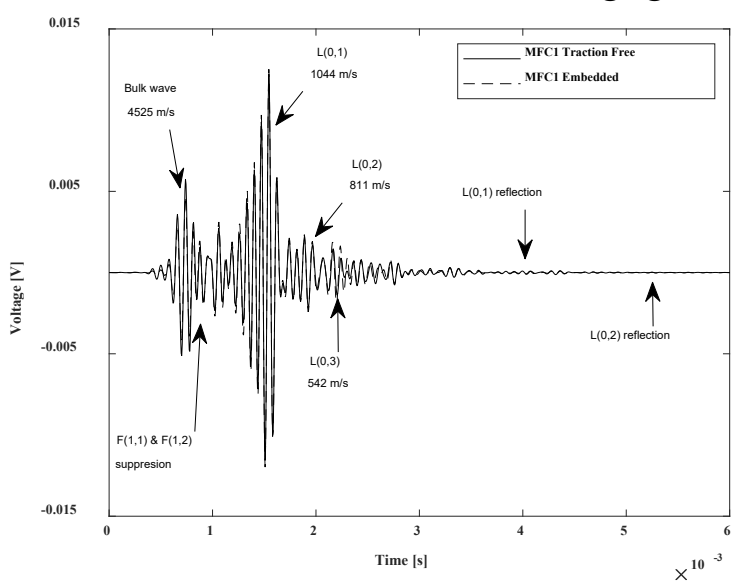

(b)

Fig. 7 Experimental results: Propagating wave modes and their reflections for traction free/embedded signals using (a) 4-Ring and (b) 8-Ring MFC actuation at $12.5 \mathrm{kHz}$.

Effect of Damage Induction. The behavior of guided waves in timber has been examined with the change in boundary conditions (traction free and embedded models) for sound wood. In this section, results from inducing damage in the timber structure (embedded section) are shown. The same boundary conditions and MFC actuation configurations were used, at $12.5 \mathrm{kHz}$ frequency. Numerical results from single MFC actuation, embedded boundary condition are displayed in 
Fig. 8 (a) for sound (solid line) and damaged timber (dashed line). From the original signal, some difference can be identified after time 3E-3 seconds. No solid identification of the damage reflection can be identified, which requires the usage of CEEMDAN to better identify the packets resulting from the damage. The first decomposed mode (IMF 1) is displayed in Fig. 8 (b) where the reflected packets from the edge of the pole and damage are indicated. Flexural and longitudinal modes' direct and reflected transmissions are indicted on the figure. The decomposed signal shows the arrival of $\mathrm{F}(1,2)$ from the damage at $1.8 \mathrm{E}-3$ seconds, which coincides with the arrival of $\mathrm{F}(1,1)$ edge reflection. Longitudinal mode $\mathrm{L}(0,1)$ reflects from the damage and arrives solely at $2.6 \mathrm{E}-3$ seconds. The packet at $3.4 \mathrm{E}-3$ seconds appears to have a higher amplitude in the damaged signal (dashed line) due to the arrival of $\mathrm{L}(0,2)$ damage reflection, which coincides with the second reflection of $\mathrm{F}(1,1)$ from the top edge of the pole. Last, longitudinal mode $\mathrm{L}(0,3)$ propagating at around $508 \mathrm{~m} / \mathrm{s}$ reflects from the damage and arrives solely at $4.35 \mathrm{E}-3$ seconds. Longitudinal modes provide more accurate information about the damage, especially due to the non-concatenated packets such as $\mathrm{L}(0,1)$ and $\mathrm{L}(0,3)$ reflections from the damage. Due to their higher speed, flexural modes' reflections seem to arrive early in the signal which results in the concatenation with other modes of lower speeds. Therefore, longitudinal modes can be solely used for the damage localization process. The numerical acquired signal from the traction free boundary condition showed similar results as the embedded, with minor differences in the amplitude of the reflected wave modes.
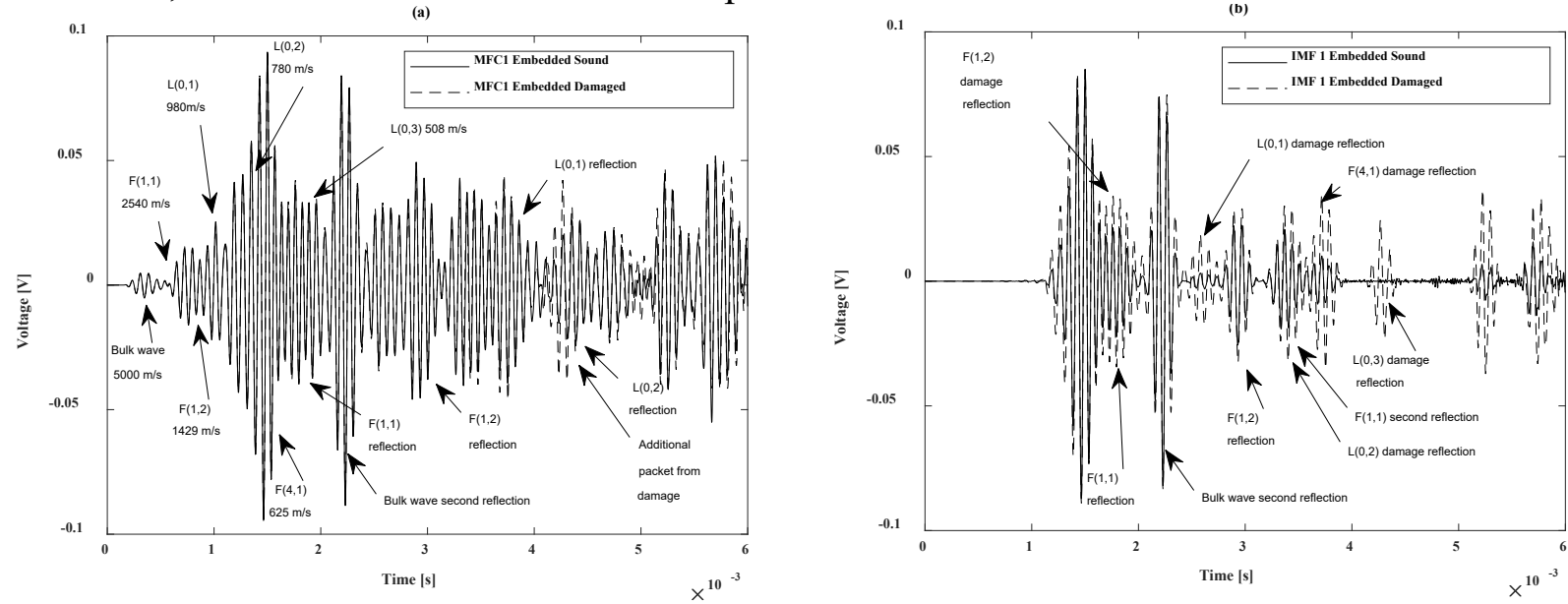

Fig. 8 Numerical results: Embedded sound (solid line) and damaged (dashed line) using single MFC actuation at $12.5 \mathrm{kHz}$ (a) original signal and (b) decomposed signal after CEEMD (IMF

1).

In the experimental validation, the induced damage in the timber structure resulted in much more complicated results than the numerical. Several knots and cracks in the experimental timber specimen cause reflections which complicates the acquired signals. Therefore, the propagating wave mode arrivals could be overlapping in most cases which makes it hard to determine the damage location for more than one mode. The decomposed signal from the embedded condition for single MFC actuation at $12.5 \mathrm{kHz}$ is shown in Fig. 9. The propagating modes are indicated on the figure with their reflections. Flexural modes $F(1,1)$ and $F(1,2)$ arrive at the beginning of the signal and reflect from the bottom edge at 2E-3 and 3E-3 seconds. Longitudinal modes L $(0,1)$ and $\mathrm{L}(0,2)$ propagate at $1140 \mathrm{~m} / \mathrm{s}$ and $845 \mathrm{~m} / \mathrm{s}$ respectively and reflect from the bottom edge of the pole. $\mathrm{L}(0,1)$ bottom edge reflection acquires a significantly low amplitude in the damaged signal due to the location of the damage between the MFC sensor and the pole's edge. Each of 
the two longitudinal modes reflect from the damage and arrive at around $3 \mathrm{E}-3$ and $3.65 \mathrm{E}-3$ second. The arrival of $\mathrm{L}(0,1)$ damage reflection coincides with the reflection of $\mathrm{F}(1,2)$ from the pole's edge, where the amplitude of the packet in the damaged signal is slightly higher. The damage can still be localized accurately using mode L(0,1). Also, the arrival of L $(0,2)$ 's damage reflection can be indicated which coincides with the arrival of knot reflection of $\mathrm{L}(0,1)$ present at 1.2 meters from the actuator and can be used for the localization process. The acquired signals from the traction free boundary condition showed similar results as the embedded. The amplitude of reflecting packet from the damage is higher for mode $\mathrm{L}(0,1)$ in the traction free condition, which might be due to the timber - soil interface at the damage location.

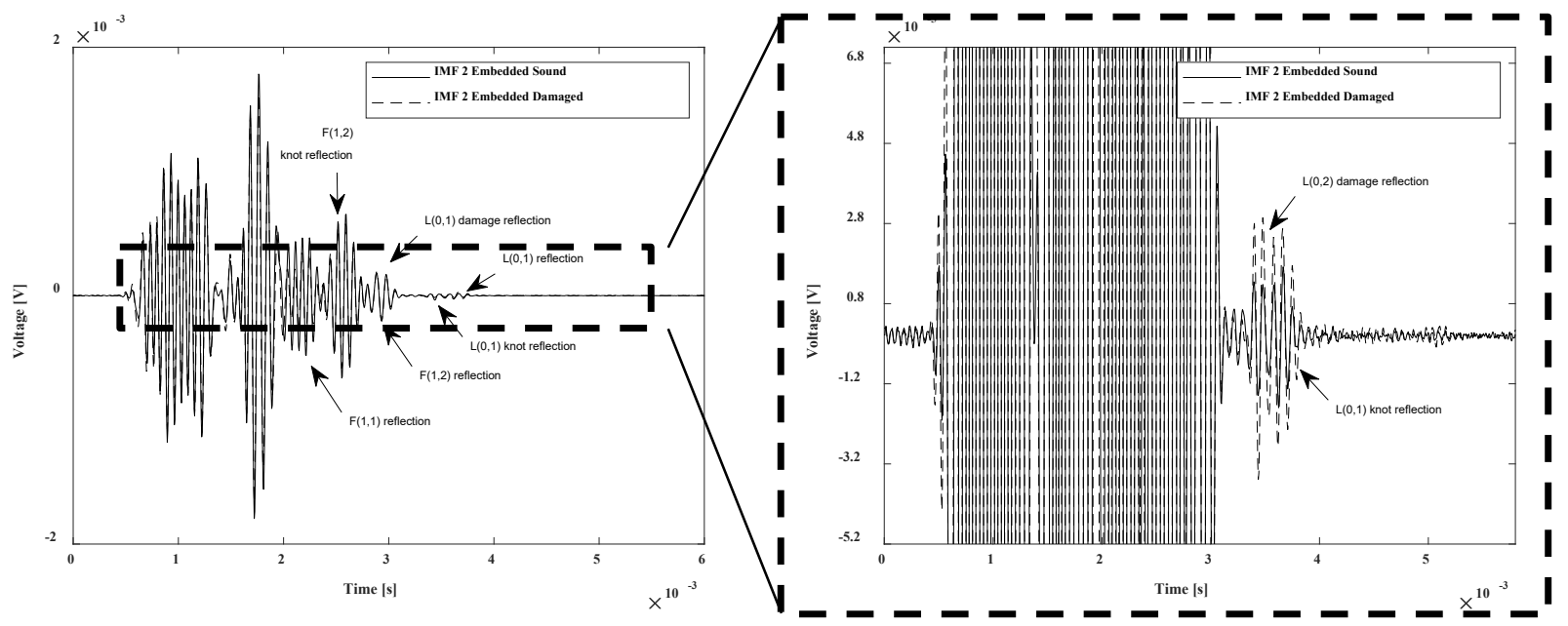

Fig. 9 Experimental results: decomposed signal after CEEMD (IMF 2) for embedded sound/damaged using single MFC actuation at $12.5 \mathrm{kHz}$.

The single MFC actuation could provide enough information regarding the presence of decay or damage inside the timber specimen. The reflected packets from the damage were identified successfully in both traction free and embedded boundary conditions. However, multiple MFC actuation might not be suitable for damage identification, especially if the damage is located axially along a certain face of the timber pole. For instance, the induced damage in the tested pole lied axially on the same straight line as the MFCs in the single actuation configuration. Therefore, actuating the 4 or 8-ring could prevent the damage reflection to be properly acquired from the sensor. This was depicted numerically and experimentally where the MFC ring was actuated in the damaged condition and compared to the results of the sound specimen.

The results of the damaged timber pole show that the ring actuation has negative effects on damage localization. Fig. 10 show the decomposed (IMF1) numerical signals in the embedded model using 4 and $8 \mathrm{MFC}$ ring actuation. The acquired results show that there is a negligible difference between the sound and damaged timber specimens. Reflection of longitudinal modes $\mathrm{L}(0,1)$ and $\mathrm{L}(0,2)$ from the damage are not captured as the single actuation shown earlier, where the expected time of arrival does not show any packet. This is depicted in the decomposed signals after CEEMD (IMF 1) shown in Fig. 10 (a-b). In the traction free model, actuating 4 and 8 MFCs lead to similar results as the embedded boundary conditions. No reflections from the damage were acquired where they do not appear in the signal, even after applying CEEMD. However, the reflections of $\mathrm{L}(0,1)$ and $\mathrm{L}(0,2)$ from the bottom edge of the pole were successfully captured and are identified on the figures in both MFC ring actuations. 


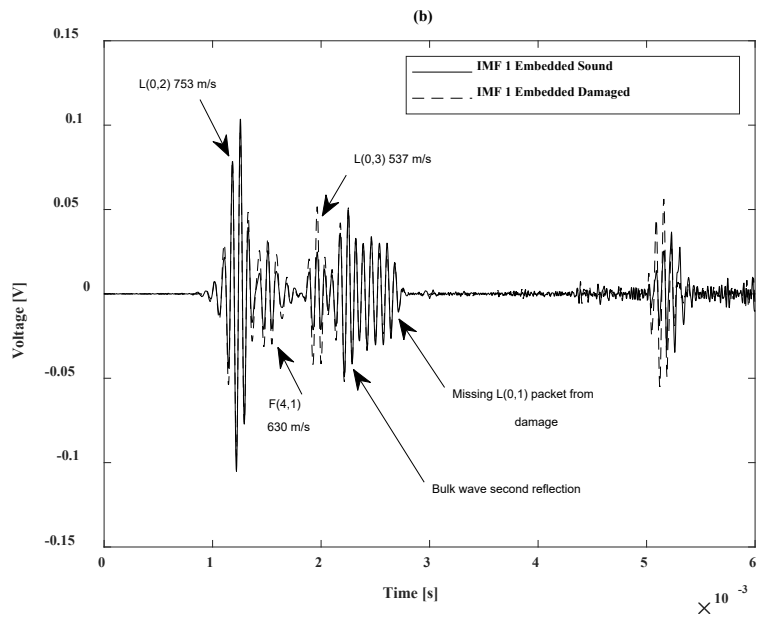

(a)

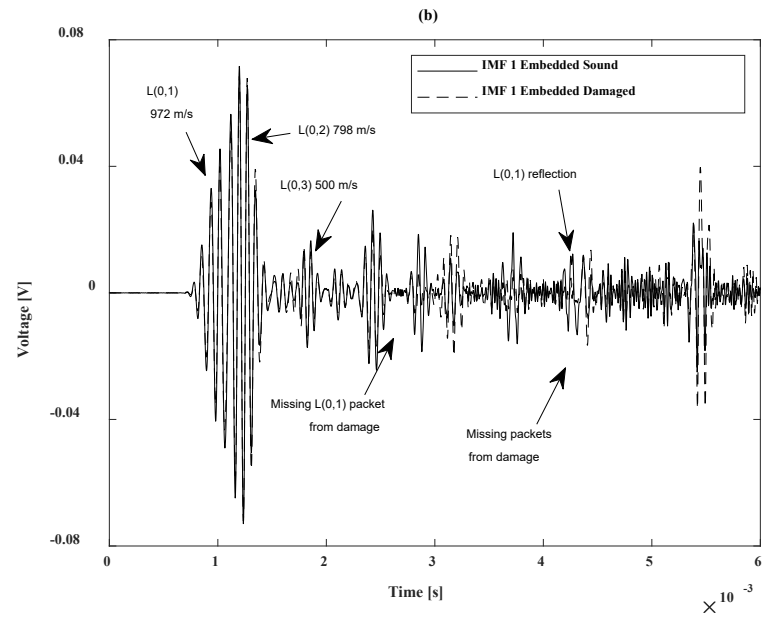

(b)

Fig. 10 Numerical results (decomposed signals after CEEMD (IMF 1)): Embedded sound (solid line) and damaged (dashed line) using (a) 4 ring MFC actuation at $12.5 \mathrm{kHz}$ and (a) 8 ring $\mathrm{MFC}$ actuation at $12.5 \mathrm{kHz}$.

In the experimental results, the MFC ring actuation also caused the reflections from the damage to be less exposed. No major difference was determined between the sound and damage timber specimens, even after performing CEEMD.

\section{Length Estimation and Damage Localization}

The estimation of embedment length and damage location can be performed using the resulting reflected packets of a selected wave mode. From the propagation velocity and arrival time of the reflections, the total propagation distance can be calculated. Fig. 11 shows a top view sketch of the pole used in the numerical and experimental validation. The reflecting packets from the bottom edge of the pole can provide an estimation of the distance between the edge and the MFC sensor. As for locating the damage, the reflections resulted can be used to estimate the distance between the damage and the MFC sensor. The actual distance between the MFC sensor and bottom edge of the pole is 1.5 meters, and between the sensor and center of the damage is $79 \mathrm{~cm}$. These values are a reference used for caldithatidglathaglistance estimation error.

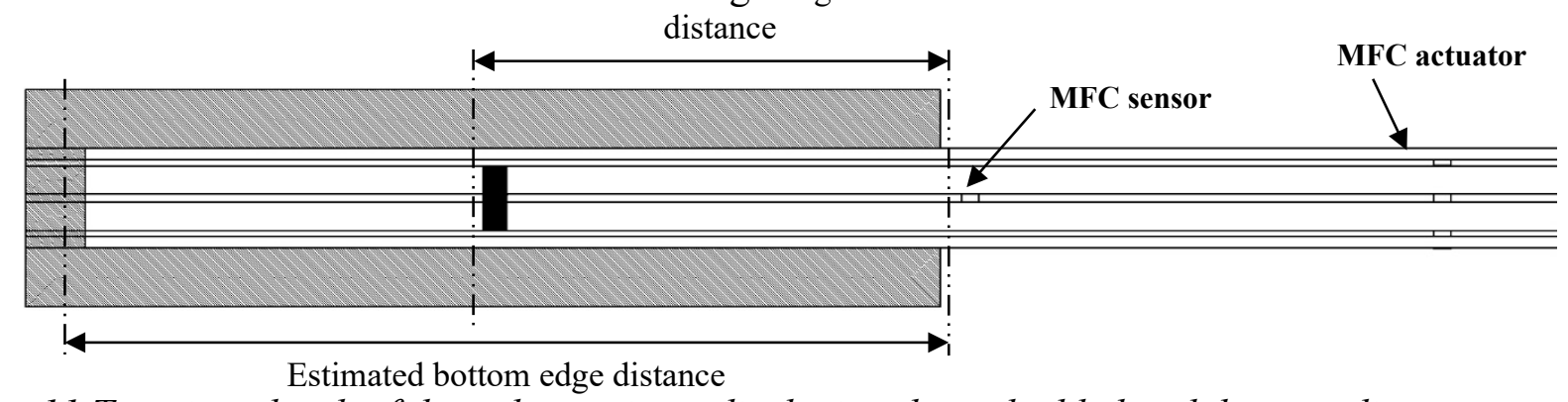

Fig. 11 Top view sketch of the pole specimen displaying the embedded and damage distances to be estimated.

The below equation (Eq. 1) is used to estimate the distance between the MFC sensor and the bottom edge, and the center of the damage. $\mathrm{V}$ is the propagation velocity of the wave mode selected. $\Delta t$ is the time difference between the first arrival of the selected mode, and the second arrival resulting from the reflection. This reflection could be either from the damage or the 
bottom edge of the pole. The total distance (in meters) indicates the propagation distance covered by the wave and must be divided by 2 .

$$
d=\frac{V \times \Delta t}{2}
$$

Several wave modes can be selected to estimate the distances required, which were shown in the results section at $12.5 \mathrm{kHz}$ frequency. However, not all modes can be used due to their complexity and dispersive nature. Longitudinal wave modes can be found in almost all cases, whether in sound/damaged timber or in multiple MFC (ring) actuation where they acquire an enhanced amplitude. Therefore, they can be used for distance estimation.

The distance between the MFC sensor and bottom edge of the pole, which corresponds to the embedment length of the pole, was determined using data from longitudinal mode $\mathrm{L}(0,1)$. This mode was selected due to its consistency in all experiments and least dispersive nature, in addition to the amplitude it acquires, which is higher than any other mode in the signal. Table 2 displays the bottom edge distance estimation using the numerical results for 8-ring MFC actuation at $12.5 \mathrm{kHz}$ excitation frequency The presence of damage in all actuation configurations causes the reflection amplitude from the bottom edge to be lower than the sound timber pole.

Table 2 Numerical results: Bottom edge distance estimation using mode $L(0,1)$ for 8 -ring $M F C$ actuation.

\begin{tabular}{|c|c|c|c|c|c|c|c|}
\hline Actuation & $\begin{array}{l}\text { Boundary } \\
\text { condition }\end{array}$ & $\begin{array}{c}1^{\text {starrival }} \\
\text { time (s) }\end{array}$ & $\begin{array}{c}2^{\text {nd }} \text { arrival } \\
\text { time (s) }\end{array}$ & $\begin{array}{l}\text { Reflection } \\
\text { amplitude } \\
\text { (mV) }\end{array}$ & $\begin{array}{c}\text { Velocity } \\
(\mathrm{m} / \mathrm{s})\end{array}$ & $\begin{array}{l}\text { Estimated } \\
\text { distance } \\
\text { (m) }\end{array}$ & $\begin{array}{c}\text { Error } \\
(\%)\end{array}$ \\
\hline \multirow{4}{*}{$\underset{\infty}{\infty}$} & $\begin{array}{c}\text { Traction } \\
\text { Free } \\
\text { Sound }\end{array}$ & 0.001023 & 0.004198 & 45.3 & 972 & 1.543 & 2.79 \\
\hline & $\begin{array}{l}\text { Embedded } \\
\text { Sound }\end{array}$ & 0.001023 & 0.004193 & 40.2 & 972 & 1.541 & 2.64 \\
\hline & $\begin{array}{c}\text { Traction } \\
\text { Free } \\
\text { Damaged }\end{array}$ & 0.001023 & 0.004198 & 35.6 & 972 & 1.543 & 2.79 \\
\hline & $\begin{array}{c}\text { Embedded } \\
\text { Damaged }\end{array}$ & 0.001023 & 0.004195 & 37.3 & 972 & 1.542 & 2.7 \\
\hline
\end{tabular}

Table 3 displays the bottom edge distance estimation using the experimental results for 8-ring MFC actuation. The application of MFC ring actuation causes the reflection amplitude of $\mathrm{L}(0,1)$ to increase compared to the single MFC actuation. Also, in the traction free damaged timber pole, the single actuation was not enough for the edge reflection to appear which resulted in a missing packet around 4E-3 seconds. In the embedded damaged pole, single actuation, the reflection from the bottom edge of the pole was captured but at a lower amplitude than the sound timber specimen. The missing packet in the damaged condition does not appear in the 4 and 8ring MFC actuation, where the distance is estimated normally. 
Table 3 Experimental results: Bottom edge distance estimation using mode L(0,1) for single, 4ring and 8-ring MFC actuation.

\begin{tabular}{|c|c|c|c|c|c|c|c|}
\hline Actuation & $\begin{array}{l}\text { Boundary } \\
\text { condition }\end{array}$ & $\begin{array}{c}1^{\text {starrival }} \\
\text { time (s) }\end{array}$ & $\begin{array}{c}2^{\text {nd }} \text { arrival } \\
\text { time (s) }\end{array}$ & $\begin{array}{c}\text { Reflection } \\
\text { amplitude } \\
(\mathrm{mV})\end{array}$ & $\begin{array}{c}\text { Velocity } \\
(\mathrm{m} / \mathrm{s})\end{array}$ & $\begin{array}{c}\text { Estimated } \\
\text { distance } \\
(\mathrm{m})\end{array}$ & $\begin{array}{l}\text { Error } \\
(\%)\end{array}$ \\
\hline \multirow{4}{*}{ م. } & $\begin{array}{c}\text { Traction } \\
\text { Free } \\
\text { Sound }\end{array}$ & 0.00151 & 0.004326 & 0.1253 & 1044 & 1.47 & 2 \\
\hline & $\begin{array}{l}\text { Embedded } \\
\text { Sound }\end{array}$ & 0.00151 & 0.004332 & 0.121 & 1044 & 1.473 & 1.79 \\
\hline & $\begin{array}{c}\text { Traction } \\
\text { Free } \\
\text { Damaged }\end{array}$ & 0.00151 & 0.004316 & 0.064 & 1044 & 1.465 & 2.35 \\
\hline & $\begin{array}{c}\text { Embedded } \\
\text { Damaged }\end{array}$ & 0.00151 & 0.004352 & 0.11 & 1044 & 1.4835 & 1.1 \\
\hline
\end{tabular}

Determining the location of the damage was performed using longitudinal mode $\mathrm{L}(0,1)$ for the single MFC actuation. Table 4 shows the damage location estimation using the numerical results acquired.

Table 4 Numerical results: Damage localization using mode L(0,1) for single MFC actuation.

\begin{tabular}{|c|c|c|c|c|c|c|c|}
\hline Actuation & $\begin{array}{l}\text { Boundary } \\
\text { condition }\end{array}$ & $\begin{array}{c}1^{\text {st }} \text { arrival } \\
\text { time (s) }\end{array}$ & $\begin{array}{c}2^{\text {nd }} \text { arrival } \\
\text { time (s) }\end{array}$ & $\begin{array}{l}\text { Reflection } \\
\text { amplitude } \\
\text { (mV) }\end{array}$ & $\begin{array}{c}\text { Velocity } \\
(\mathrm{m} / \mathrm{s})\end{array}$ & $\begin{array}{l}\text { Estimated } \\
\text { distance } \\
\text { (m) }\end{array}$ & $\begin{array}{c}\text { Error } \\
(\%)\end{array}$ \\
\hline \multirow{2}{*}{ ڤั) } & $\begin{array}{l}\text { Traction } \\
\text { Free } \\
\text { Damaged }\end{array}$ & 0.001018 & 0.00266 & 3.107 & 979 & 0.804 & 1.71 \\
\hline & $\begin{array}{c}\text { Embedded } \\
\text { Damaged }\end{array}$ & 0.001018 & 0.002673 & 2.83 & 979 & 0.81 & 2.48 \\
\hline
\end{tabular}

Estimating the damage location using the experimental results is shown in Table 5 for the single MFC actuation. In the 4-ring actuation - traction free condition, the reflecting packet from the damage was identified but with a higher error of $7.8 \%$. It does not appear in the 4-ring embedded boundary condition, nor in any of the 8-ring MFC actuations.

Table 5 Experimental results: Damage localization using mode L(0,1) for single MFC actuation.

\begin{tabular}{c|ccccccc}
\hline Actuation & $\begin{array}{c}\text { Boundary } \\
\text { condition }\end{array}$ & $\begin{array}{c}\mathbf{1}^{\text {starrival }} \\
\text { time (s) }\end{array}$ & $\begin{array}{c}\mathbf{2}^{\text {nd arrival }} \text { time (s) } \\
\text { time }\end{array}$ & $\begin{array}{c}\text { Reflection } \\
\text { amplitude } \\
(\mathbf{m V})\end{array}$ & $\begin{array}{c}\text { Velocity } \\
(\mathbf{m} / \mathbf{s})\end{array}$ & $\begin{array}{c}\text { Estimated } \\
\text { distance } \\
(\mathbf{m})\end{array}$ & $\begin{array}{c}\text { Error } \\
\mathbf{( \% )}\end{array}$ \\
\hline \multirow{5}{*}{$\begin{array}{c}\text { Traction } \\
\text { Free }\end{array}$} & 0.001446 & 0.002928 & 0.42 & 1140 & 0.845 & 6.48 \\
& $\begin{array}{c}\text { Damaged } \\
\text { Embedded } \\
\text { Damaged }\end{array}$ & 0.001446 & 0.002928 & 0.22 & 1140 & 0.8245 & 6.48 \\
\hline
\end{tabular}

It was mentioned in the Effect of Damage Induction section that reflections from other modes were captured and might predict accurately the location of the damage. For instance, in some cases, longitudinal mode $\mathrm{L}(0,2)$ appears to reflect from the damage. In the experimental single MFC actuation - embedded condition, reflection of $\mathrm{L}(0,2)$ from the damage arrives at 3.7E-3 seconds providing a damage location estimation with $0.886 \%$ error. This mode does not appear 
in the 4 and 8-ring MFC actuation experimental results. However, in the numerical results, the damage reflections of mode $\mathrm{L}(0,2)$ were acquired in the 8-ring MFC actuation. The damage location was estimated in the traction free and embedded boundary conditions with a $2.75 \%$ error. In addition, damage reflections of flexural modes $\mathrm{F}(1,1)$ and $\mathrm{F}(1,2)$ were also captured in the single MFC actuation from the numerical results in both boundary conditions simulated. The location of the damage estimated using $\mathrm{F}(1,1)$ and $\mathrm{F}(1,1)$ resulted in an error of $8.8 \%$ and $5 \%$ respectively. This indicates how the flexural modes are much more complicated than longitudinal modes, due to their highly dispersive nature, which results in inaccuracy when estimating the location of the damage. Assesing the presence of decay/damage in the timber structure proved to be more adequate using the single MFC actuation. Therefore, it is proposed to actuate each MFC in the ring solely at a time, while acquiring the signals on the same plane of actuation. This requires the installment of a sensor ring with the same number of MFCs as the actuator ring.

\section{Conclusions}

In this study, the embedded length of timber utility pole and the presence of damage/decay in the embedded section were scrutinized numerically and experimentally by the use of guided waves (GWs). Macro Fiber Composites (MFCs) proved to be a convenient tool for generating/sensing GWs in timber structures, especially due to their reliability and flexibility to be coupled on curved and rough surfaces. Evaluating the structure's health state was performed with the variation of external boundary conditions, such as soil embedment, and the application of an MFC ring coupled around the pole's circumference. The ring ensured the actuation of the wave modes of interest, such as longitudinal mode $\mathrm{L}(0,1)$, with an enhanced amplitude and was recommended for estimating the embedded depth of the pole. The estimation yielded an accuracy of $97 \%$ in both numerical and experimental results, even with the presence of damage in the timber structure. Determining the location of the damage in the embedded section was performed using the single MFC actuation and data from mode $\mathrm{L}(0,1)$ with an error of less than $7 \%$.

\section{Acknowledgments}

We acknowledge the financial support of the University Research Board at the American University of Beirut for their Award \#103780.

\section{References}

[1] EP DeGarmo, JT Black, RA Kohser and BE Klamecki, "Materials and process in manufacturing, 9th ed." Prentice Hall, Upper Saddle River, pp, 1997.

[2] M Subhani, "A Study on the Behaviour of Guided Wave Propagation in Utility Timber Poles”, University of Technology Sydney, 2014.

[3] U Dackermann, Y Yu, E Niederleithinger, J Li and H Wiggenhauser, "Condition assessment of foundation piles and utility poles based on guided wave propagation using a network of tactile transducers and support vector machines”, Sensors 17(12), pp 2938, 2017.

https://doi.org/10.3390/s17122938

[4] U Dackermann, B Skinner and J Li, "Guided wave-based condition assessment of in situ timber utility poles using machine learning algorithms”, Structural Health Monitoring 13(4), pp 374-388, 2014. https://doi.org/10.1177/1475921714521269 
[5] Y Yu, U Dackermann, J Li and N Yan, "Guided-wave-based damage detection of timber poles using a hierarchical data fusion algorithm", Proc. of Australasian Conference on the Mechanics of Structures and Materials, Lismore, pp 1203-1208, 2014.

[6] B Pavlakovic and M Lowe, "Disperse Software Manual Version 2.0. 1 6B", Imperial College, London, UK, pp, 2003.

[7] F Seco and AR Jiménez, "Modelling the generation and propagation of ultrasonic signals in cylindrical waveguides, Ultrasonic waves, 1", InTechOpen, pp 1-28, 2012. https://doi.org/10.5772/29804

[8] DE Kretschmann, "Mechanical properties of wood, Wood handbook: wood as an engineering material, 5", Forest Products Laboratory, pp 5.1-5.46, 2010.

[9] AB Thien, "Pipeline structural health monitoring using macro-fiber composite active sensors", Dissertation, University of Cincinnati, United States, 2006. https://doi.org/10.2172/883462

[10]J El Najjar and S Mustapha, "Understanding the guided waves propagation behavior in timber utility poles", Construction and Building Materials, pp 1-21, 2020.

[11]C Multiphysics, "Introduction to COMSOL Multiphysics ${ }^{\circledR} ”$, COMSOL Multiphysics, Burlington, MA, accessed Feb 9, pp 2018, 1998.

[12] S Marburg, "Six boundary elements per wavelength: Is that enough?", Journal of Computational Acoustics 10(01), pp 25-51, 2002. https://doi.org/10.1142/S0218396X02001401

[13] S Mustapha and L Ye, "Leaky and non-leaky behaviours of guided waves in CF/EP sandwich structures", Wave Motion 51(6), pp 905-918, 2014.

https://doi.org/10.1016/j.wavemoti.2014.03.004

[14]D Bieker and S Rust, "Non-destructive estimation of sapwood and heartwood width in Scots pine (Pinus sylvestris L.)", Silva Fennica 44(2), pp 267-273, 2010.

https://doi.org/10.14214/sf.153

[15] MA Fakih, S Mustapha, J Tarraf, G Ayoub and R Hamade, "Detection and assessment of flaws in friction stir welded joints using ultrasonic guided waves: experimental and finite element analysis", Mechanical Systems and Signal Processing 101, pp 516-534, 2018. https://doi.org/10.1016/j.ymssp.2017.09.003

[16]J El Najjar and S Mustapha, "Understanding the Wave Propagation Behavior in Timber Structures towards Application in the Assessment of Utility Timber Poles", Civil Structural Health Monitoring, pp, 2020. https://doi.org/10.1007/s13349-020-00417-0 